\title{
Extreme value modelling of storm damage in Swedish forests
}

\author{
A. Bengtsson ${ }^{1}$ and C. Nilsson ${ }^{2}$ \\ ${ }^{1}$ Mathematical Statistics, Centre for Mathematical Sciences, Lund University, P.O. Box 118, 22100 Lund, Sweden \\ ${ }^{2}$ Department of Physical Geography and Ecosystems Analysis, Geobiosphere Science Centre, Lund University, \\ Sölvegatan 12, 22362 Lund, Sweden
}

Received: 27 February 2007 - Revised: 27 June 2007 - Accepted: 5 September 2007 - Published: 12 September 2007

\begin{abstract}
Forests cover about $56 \%$ of the land area in Sweden and forest damage due to strong winds has been a recurring problem. In this paper we analyse recorded storm damage in Swedish forests for the years 1965-2007. During the period 48 individual storm events with a total damage of $164 \mathrm{Mm}^{3}$ have been reported with the severe storm on 8 to 9 January 2005, as the worst with $70 \mathrm{Mm}^{3}$ damaged forest. For the analysis, storm damage data has been normalised to account for the increase in total forest volume over the period.

We show that, within the framework of statistical extreme value theory, a Poisson point process model can be used to describe these storm damage events. Damage data supports a heavy-tailed distribution with great variability in damage for the worst storm events. According to the model, and in view of available data, the return period for a storm with damage in size of the severe storm of January 2005 is approximately 80 years, i.e. a storm with damage of this magnitude will happen, on average, once every eighty years.

To investigate a possible temporal trend, models with time-dependent parameters have been analysed but give no conclusive evidence of an increasing trend in the normalised storm damage data for the period. Using a non-parametric approach with a kernel based local-likelihood method gives the same result.
\end{abstract}

\section{Introduction}

During the last three years Swedish forests have been struck by two major storms. The earlier one, on 8 January 2005, named "Erwin/Gudrun", caused the largest amount of reported storm damage ever in Sweden (Skogsstyrelsen, 2006a). In total 270000 ha of forest were demolished, adding to approximately $70 \mathrm{Mm}^{3}$ of damaged timber, i.e. the size of

Correspondence to: A. Bengtsson

(ab@maths.lth.se) damage was almost equal to $2 / 3$ of the total reported forest damage for the 20th century (Nilsson et al., 2004).

The more recent storm, on 14 January 2007, nicknamed "Per", was accountable for $12 \mathrm{Mm}^{3}$ of damage in southSwedish forests. Both storms have also resulted in severe secondary destruction of important infrastructures such as power supply, telecommunications, roads and railway systems (Skogsstyrelsen, 2006c).

The intensity of "Gudrun" was extreme. Still the southern part of Sweden has suffered from earlier storms of approximately the same magnitude during the last hundred years; in 1902 and in 1969 (Alexandersson and Ivarsson, 2005). Concern has been raised within the forest industry and the Swedish community on how often these forest damaging storms return, and their associated risks and implications for society (Skogsstyrelsen, 2006b).

Today, Swedish forests cover approximately 22.9 million out of 41 million hectares, or $55.8 \%$, of the land. Almost all of the forested land is located within the boreal and hemiboreal zone and coniferous trees dominate. The most common species, measured in total standing volume over bark, are Norway spruce (Picea abies Karst.) (42.8\%) followed by Scots pine (Pinus sylvestris L.) (38.2\%) and birch (Betula spp.) (10.9\%) (Skogsstyrelsen, 2006c). Documented damage in Swedish forests, due to wind, has been presented in the annual reports from the Regional Forest Boards since 1910. A compilation of available records of forest storm damage in Sweden since year 1795 has been made by Holmberg (2005), and Nilsson et al. (2004) have organized a regionally resolved dataset of reported storm damage covering 1901 to 2000.

Damage reports have increased in frequency from the beginning of the 20th century to the mid-sixties, which also includes an increase in the reported volume of damage (see Fig. 1).

Despite the available data, the literature present few studies on the return period of storm damage in Swedish forests.

Published by Copernicus Publications on behalf of the European Geosciences Union. 

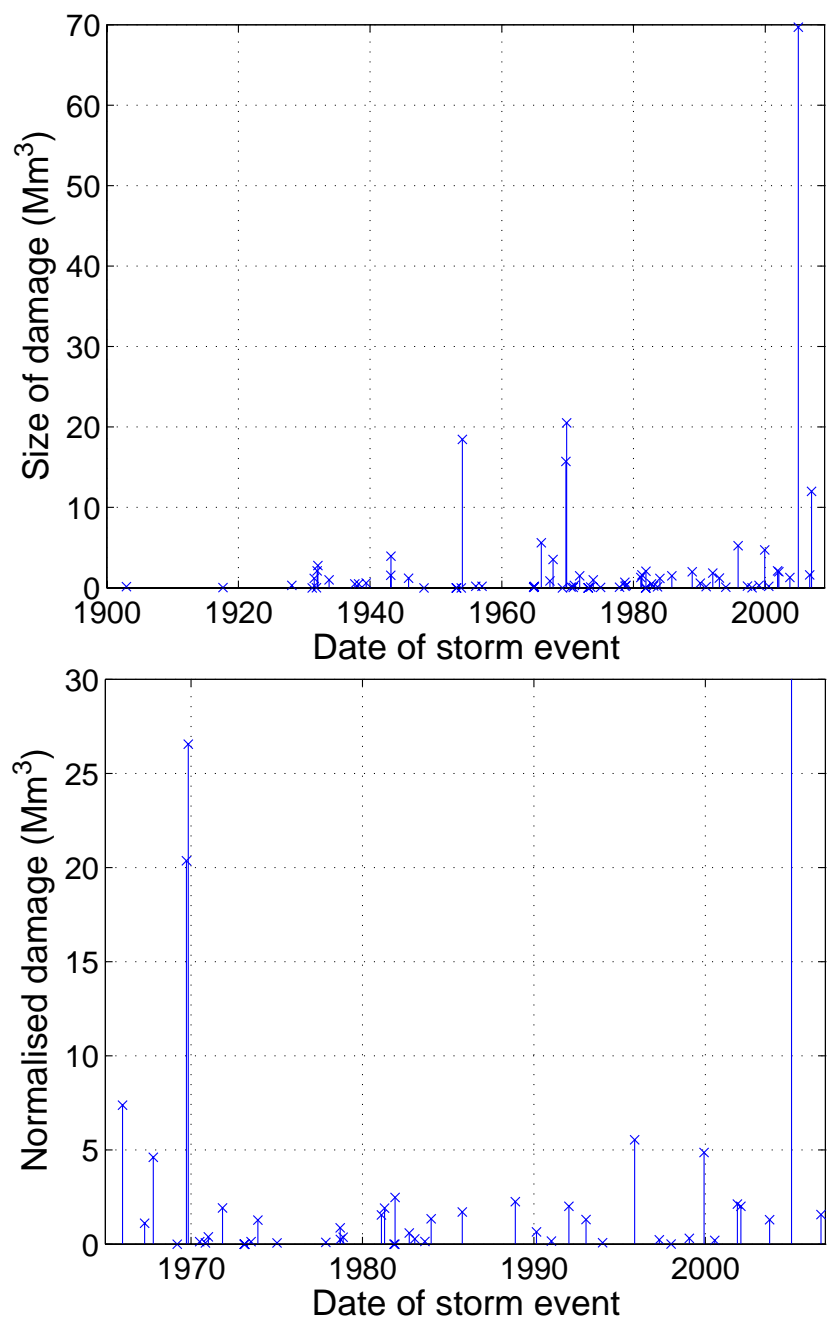

Fig. 1. Storm damage in Swedish forests for years 1900-2007 (top) and damage years 1965-2007 normalised for the increase in total volume with year 2000 as norm (bottom). Note: The normalised storm damage year $2005\left(68.6 \mathrm{Mm}^{3}\right)$ exceeds axis limit.

An early compilation was done by Sotter (1956), who gathered data, from 1871 to 1955 , on forest storm damage reported yearly by the Regional Forestry Boards, the Swedish Forest Service (Domänsstyrelsernasårsberättelser) and the Swedish counties. Sotter (1956) found that severe storm damage, defined as damage exceeding 4 to above $10 \mathrm{~m}^{3} / \mathrm{ha}$ productive forest, had a return period of 10 years. However, he remarks that the significance is low, since the data only includes 3 catastrophic storms with damage exceeding $10 \mathrm{~m}^{3} / \mathrm{ha}$ (years 1931, 1943 and 1954) within the 85 years in the study.

There are many factors contributing to an explanation of why a certain tree is damaged in a storm. Naturally, the main cause of wind damage in forests is due to strong gusts. However, there is no observational evidence for an increasing long term trend in storminess for Scandinavia during the last century (Bärring and von Storch, 2004; Alexandersson et al., 2000) which could explain the increased number of reports and damage. Instead the increase in reported storm damage, both on a European scale and in Sweden, has been related to an increase in forest volume and area of coniferous forest, especially Norway spruce (Schelhaas et al., 2003; Nilsson et al., 2004). In Sweden the total forest volume has increased, almost linear, from $1747 \mathrm{Mm}^{3}$ year 1926 to $2982 \mathrm{Mm}^{3}$ year 2000 (NFI06). For the south part of Sweden, Götaland, the amount of Norway spruce has increased in relation to Scots pine, although, for Sweden as a whole, the relation between the amount of Norway spruce, Scots pine and broad-leaves has been stable over the period (Skogsstyrelsen, 2006b).

An important factor which contributes to the susceptibility of a tree to strong wind is management practices, as synthesized by Persson (1975), Peltola et al. (1999a), Venäläinen et al. (2004), Peltola et al. (2004). Forest management influences the tree environment by regulating tree species, tree height and stand density with e.g. plantation, thinning or clearing. The root depth and width are also affected by the management practices, and with an increased wind stress this can lead to rupture or uprooting of a tree (Coutts et al., 1999; Peltola et al., 1999b; Danjon et al., 2005). Further, the general wind exposure of a forest stand, the soil properties and soil chemistry, together with the acclimatization of the trees, all which are determined by the location of the forest in the landscape, influence the ability of a single tree to cope with strong winds.

Apart from the explanations above, Schelhaas et al. (2003) has suggested uncertainty in data as a reason for increased storm damage in Europe, such that the increase may reflect an increase in number of reports rather than an actual increase in forest damage. The uncertainty in data also applies for Swedish records of storm damage data, where one example is the 1902 storm in Götaland, of which written reports speak of massive damage (Hollgren, 1903) but the reported damage is only $0.15 \mathrm{Mm}^{3}$ (Holmberg, 2005).

Forest damage due to strong winds, on a larger scale, is by nature relatively rare and available data of these events is scarce. Modelling wind-storm damage with conventional statistical methods such as regression models or standard non parametric methods, is inefficient or even inappropriate for the tail of the distribution. To be able to handle this problem some model assumptions of the regularity of the tail of the distribution have to be made. Extreme Value Theory (EVT) presents these theoretically well founded assumptions. A good introduction to EVT is given in the book by Coles (2001) and more theoretically in Leadbetter et al. (1983).

In this paper data of storm damage in Swedish forest for the period 1965-2007 is analysed using statistical extreme value theory. Data is fitted to a Poisson point process model with generalised Pareto distributed excesses. Using the model the likelihood of severe storm damage is quantified. A possible increasing temporal trend is investigated 
by using time dependent model parameters as well as with a non-parametric kernel method.

The paper begins with a section describing the storm damage data followed by a section presenting the model. The results from the analysis are given in the proceeding section and the paper concludes with a discussion and conclusions.

\section{Data}

Data on wind damaged forest comes from a regionally resolved compilation of reported storm damage in Swedish forests, covering years 1900 to 2000 . The data is based on notes and reports to the Swedish National Forestry Board, and articles from national Swedish forestry press as described by Nilsson et al. (2004). This dataset has been updated to include damage during the years of 2001 to 2007.

In this paper damage data for the later period, year 1965 to 2007 , is further analysed. Damage has been normalised for the increase in total forest volume by multiplication of each individual damage with the ratio of total forest volume in year 2000 to total forest volume in the year of damage. The normalised storm damage is plotted in Fig. 1 (bottom). As seen from the plot, the frequency of forest damaging storms is approximately constant for the period 1965-2007, with an average of 1.14 storms reported per year (storm events with zero damage corresponds to damage reports with no estimated damage size). This can be compared with data for the preceding period, in which there is a strong increase in frequency of reported storm damage, see Fig. 1 (top). Average for the period 1901-1964 was 0.38 storms per year.

Judging from Fig. 1 (top), also severity of storm damage seems to have increased. However, damage estimates from the earlier years are, as discussed in the introduction, very uncertain. During the period 1900 to 2007 there have been five storms with damage exceeding $10 \mathrm{Mm}^{3}$, year 1954, 1969 (two storms), 2005 and 2007, with a damaged volume of 18.4, 15.7, 20.5, 69.7 and $12 \mathrm{Mm}^{3}$ (cubic metre over bark), respectively.

\section{Statistical extreme value theory}

\subsection{Poisson point process model}

Since reported storm damage only reflects major storm events it is natural to use a model describing damage exceeding a certain threshold, which we denote $u$. Let $T_{i}$ denote time and $X_{i}$ size of damage for the $i$ th storm with damage exceeding level $u$ in the time period $\left[t_{a}, t_{b}\right]$. We say that the sequence of storm damage events $\left(T_{1}, X_{1}\right), \ldots\left(T_{N_{A}}, X_{N_{A}}\right)$, forms a two-dimensional point process on the set $A=\left[t_{a}, t_{b}\right] \times(u, \infty)$, with $N_{A}$ equal to the number of points in $A$. For a homogeneous process, assuming independent events, it can be shown that the point process for a sufficiently high threshold may be approximated by a
Poisson process with intensity $\lambda$, i.e. the number of points $N_{A}$ is Poisson distributed with expectation $\mathrm{E}\left[N_{A}\right]=\left(t_{b}-t_{a}\right) \lambda$. Inter-event times, $T_{i+1}-T_{i}$, in a Poisson process are independent and exponentially distributed with expectation $1 / \lambda$. Furthermore, the distribution of excesses, $X_{i}-u$, is approximately generalised Pareto with distribution function

$\mathrm{P}\left(X_{i}-u \leq z \mid X_{i}>u\right)=1-\left(1+\xi \frac{z}{\sigma}\right)^{-1 / \xi}$,

where $\xi,-\infty<\xi<\infty$, is a shape parameter and $\sigma, \sigma>0$, is a scale parameter. If $\xi<0$ the distribution of excesses is bounded from above by $-\frac{\sigma}{\xi}$, whereas in the heavy tailed case, i.e. $\xi>0$, there is no upper bound. With $\xi=0$ the generalised Pareto distribution is equal to the exponential distribution.

From Eq. (1) it follows that the conditional distribution, given a higher threshold $\tilde{u}=u+v, v>0$, is

$\mathrm{P}\left(X_{i}-\tilde{u} \leq z \mid X_{i}>\tilde{u}\right)=1-\left(1+\xi \frac{z}{\sigma+v \xi}\right)^{-1 / \xi}$.

The shape parameter $\xi$ is invariant under an increase in threshold, whereas the scale parameter $\sigma$ increases linear with $v$. Similarly, excesses above $\tilde{u}$ forms a Poisson process with intensity $\tilde{\lambda}=\lambda(1+\xi v / \sigma)^{-1 / \xi}$. Thus, the model is stable under an increase in threshold.

The choice of threshold is important. With a high threshold the bias of the model is reduced but since this gives fewer data the variance of the estimated model parameters becomes larger. Although techniques have been developed to choose an appropriate threshold the choice is still somewhat subjective. The standard method is to fit the model for a range of thresholds and then choose the lowest threshold above which parameter estimates are approximately stable.

To make inference for the model parameters we use the Maximum Likelihood (ML) method. It has been argued that the probability weighted moments method has better small sample properties, however studies show that it may have a bias in the estimates when modelling storm damage which in other studies has shown to have heavy tailed distribution with $\xi$ values above 0.5 (Rootzén and Tajvidi, 1997).

\subsection{Damage quantiles and medians}

Using Eq. (2) and the assumption of a Poisson process, the upper $p$-quantiles, $x_{T, p}$, of the maximum damage from an individual storm in a time period of length $T$, can be calculated as

$x_{T, p}=u+\frac{\sigma}{\xi}\left[\frac{(\lambda T)^{\xi}}{(-\log (1-p))^{\xi}}-1\right]$.

Furthermore, the median $m(\tilde{u})$ of a damage exceeding level $\tilde{u}, \tilde{u}>u$, is equal to

$m(\tilde{u})=\left(u-\frac{\sigma}{\xi}\right)\left(1-2^{\xi}\right)+\tilde{u} 2^{\xi}$. 

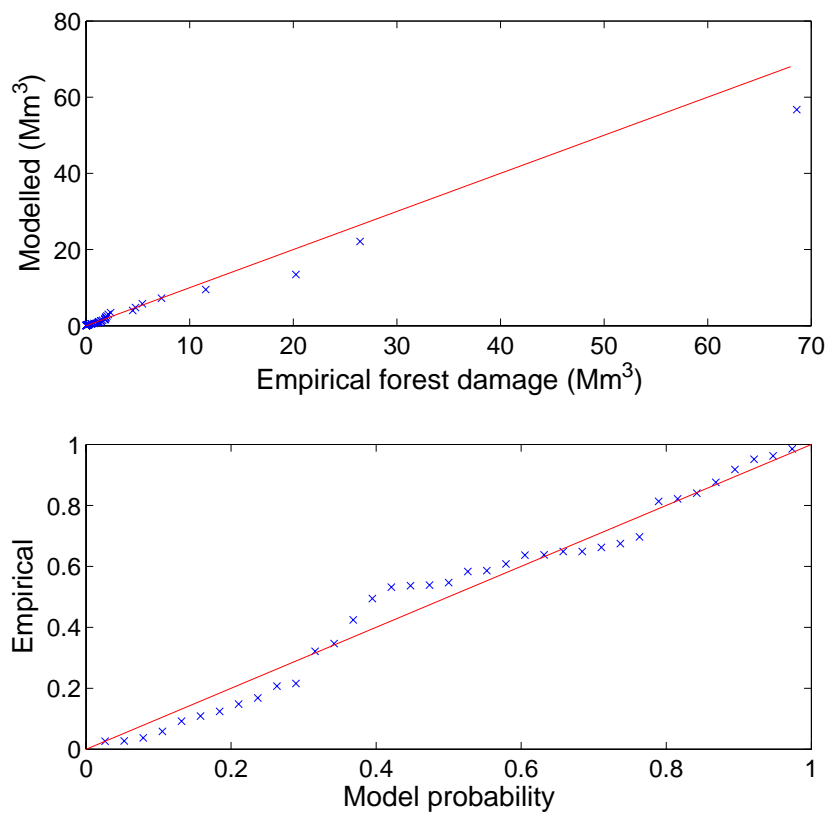

Fig. 2. Estimated shape parameter, $\xi$, (top) and scale parameter, $\sigma$, (bottom) together with corresponding $90 \%$ confidence intervals for thresholds $u=[0.05,1.8] \mathrm{Mm}^{3}$.

\subsection{Non-stationary processes}

Although, the convergence of the model for a non-stationary process can not be proved in general by EVT, it is possible to extend the stationary model to a non-stationary case with time dependent model parameters. This allows us to model a temporal trend caused by e.g. long-term climate changes. The different models considered are

(i) $\quad \sigma(t)=\sigma_{0}+\sigma_{1} t \quad$ (linear in scale)

(ii) $\xi(t)=\xi_{0}+\xi_{1} t \quad$ (linear in shape)

(iii) $\left\{\begin{array}{l}\sigma(t)=\sigma_{0}+\sigma_{1} t \\ \xi(t)=\xi_{0}+\xi_{1} t\end{array} \quad\right.$ (linear in scale and shape)

In addition to the parametric approach above we also used a non-parametric method which uses a kernel function to calculate a "local" log-likelihood (Hall and Tajvidi, 2000; Davison and Ramesh, 2000). Given the observed damage events, $\left(t_{1}, x_{1}\right), \ldots,\left(t_{n}, x_{n}\right)$, exceeding threshold $u$ in a time interval $\left[t_{a}, t_{b}\right]$, the parameter estimates, $\hat{\sigma}(t), \hat{\xi}(t)$ and $\hat{\lambda}(t)$ at time $t$ are obtained by maximising the log-likelihood expression

$$
\begin{aligned}
& l(\sigma, \xi, \lambda \mid t)= \\
& -\sum_{i=1}^{n}\left[\log (\sigma)+\left(1+\frac{1}{\xi}\right) \log \left(1+\xi \frac{x_{i}-u}{\sigma}\right)\right] K\left(\frac{t-t_{i}}{h}\right) \\
& -\sum_{i=1}^{n}\left[\left(t_{i-1}-t_{i}\right) \lambda-\log (\lambda)\right] K\left(\frac{t-t_{i}}{h}\right),
\end{aligned}
$$

with respect to $\sigma, \xi$ and $\lambda$, and where $t_{0}=t_{a} . K(\cdot)$ is the kernel function and the parameter $h$ is called the band-

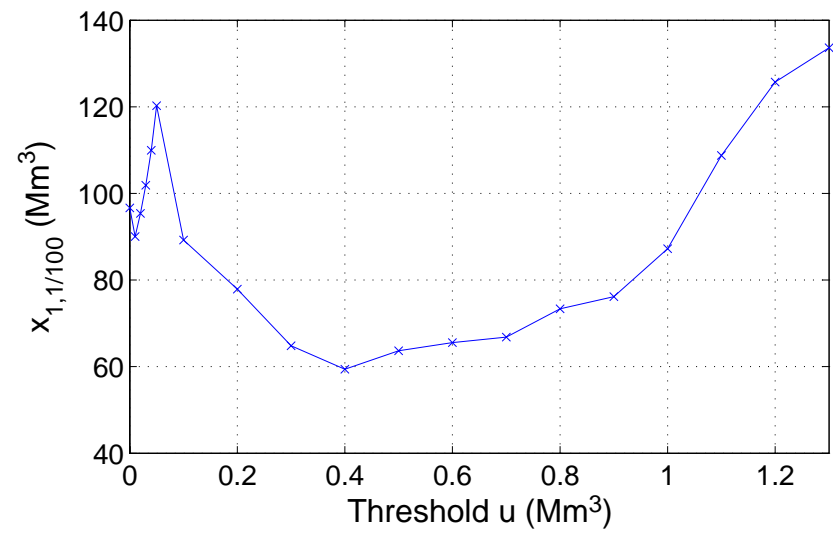

Fig. 3. Median-unbiased quantile (top) and probability (bottom) plots for a generalised Pareto distribution with estimated parameters $\hat{\xi}=1.00$ and $\hat{\sigma}=1.04 \mathrm{Mm}^{3}$.

width. A standard kernel function is the biweight kernel $K(x)=\frac{15}{16}\left(1-x^{2}\right)^{2}$ for $|x| \leq 1$.

The interpretation of return levels, Eq. (3), and median excesses, Eq. (4), becomes difficult for a non-stationary process and is outside the scope of this paper.

\section{Results}

\subsection{Model inference}

To choose an appropriate threshold the Poisson point process model is fitted for a range of thresholds. In Fig. 2 ML-estimates of the shape, $\xi$, and scale parameter, $\sigma$, for $u=[0.05,1.8] \mathrm{Mm}^{3}$ are plotted together with corresponding 90\% confidence intervals. Considered the limited number of available damage events the ML-estimates appear to be reasonably stable and a threshold of $u=0.1 \mathrm{Mm}^{3}$ is chosen. The number of damage events exceeding this level is 37. This give estimates, $\hat{\xi}=1.00(0.43,1.57)$ and $\hat{\sigma}=1.04(0.59,1.83) \mathrm{Mm}^{3}$ with $90 \%$ confidence intervals in parenthesis. The estimated intensity for storm damage events exceeding $u=0.1 \mathrm{Mm}^{3}$ is $\hat{\lambda}=0.88(0.69,1.06)$ year $^{-1}$. Since a $90 \%$ confidence interval for $\xi$ does not cover zero there is a strong support for a heavy-tailed distribution.

Diagnostic plots, such as the median-unbiased quantile plot and the probability plot in Fig. 3, show good fit, although there is some deviation from the model in the quantile plot for the three most severe storm damage events, indicating a slightly heavier tail. However, the variability of the most extreme events is large for the generalised Pareto distribution with shape parameter close to one and thus these events are likely to deviate from the straight line. The difference between the probability plot and the quantile plot is just a transformation of scale and comparing the two plots it can be seen that the deviation from the model in the quantile plot for 
Table 1. Estimated quantiles in $\mathrm{Mm}^{3}$ for different risk levels and time periods using parameter estimates $\hat{\sigma}=1.04 \mathrm{Mm}^{3}, \hat{\xi}=1.00$ and $\hat{\lambda}=0.88$ year $^{-} 1$.

\begin{tabular}{llll}
\hline Risk & 1 year & 2 years & 5 years \\
\hline $20 \%$ & 3.1 & 7.2 & 19 \\
$10 \%$ & 7.7 & 16 & 42 \\
$5 \%$ & 17 & 34 & 87 \\
\hline
\end{tabular}

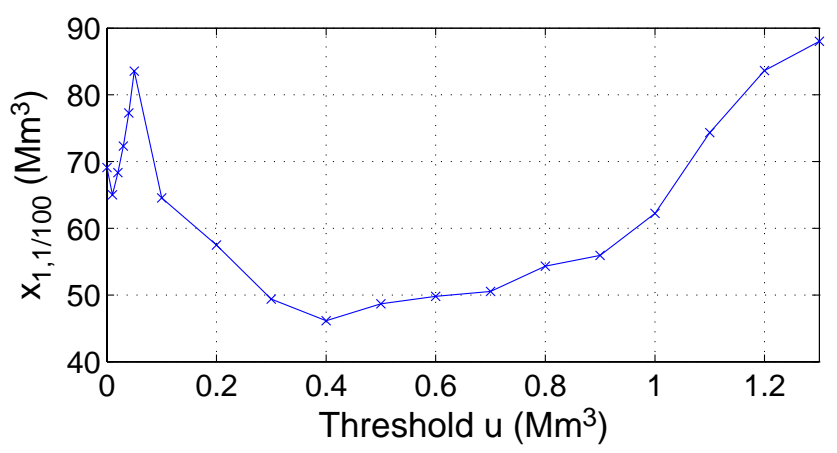

Fig. 4. The theoretical hundred year storm damage defined as the quantile $x_{1,1 / 100}$, plotted as a function of chosen threshold.

the three largest damage events corresponds to a very small difference in probability.

\subsection{Damage quantiles}

Using Eq. (3) the hundred year storm damage is computed by $x_{T, p}=x_{1,1 / 100}$. This is approximately equal to the level exceeded, on average, once every hundred years. With the chosen threshold the theoretical hundred year storm damage is $89 \mathrm{Mm}^{3}$. The return period for a storm with damage equal in size with the damage caused by the severe storm on 8 to 9 January 2005, in southern Sweden is approximately 80 years. In Table 1 quantiles for some different probabilities and time periods are given. Because of the uncertainty in parameter estimates, due to the small number of observations and choice of threshold, the computed quantile values should only be used to give the order of magnitude of damage, especially for long time periods and small probabilities. This is illustrated in Fig. 4 where the estimated hundred year storm damage is plotted as a function of chosen threshold.

\subsection{Trend analysis}

To assess a possible trend in frequency, inter-event times between succeeding events exceeding $u=0.1 \mathrm{Mm}^{3}$, are plotted in Fig. 5 together with a generalised linear model with a reciprocal link function. The generalised linear model indicates a slightly decreasing intensity with similar results for

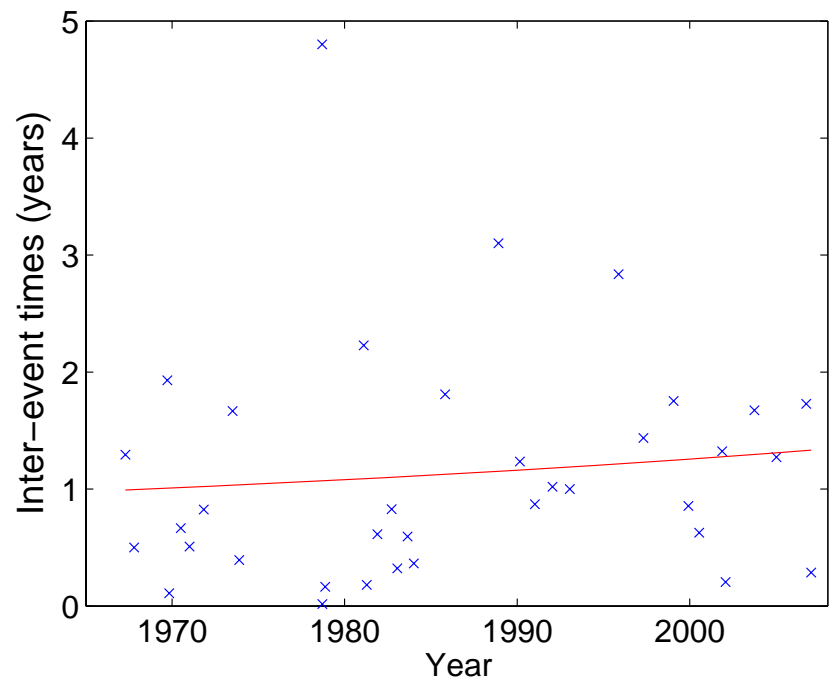

Fig. 5. Inter-event times for damage exceeding $0.1 \mathrm{Mm}^{3}$ for years 1965-2007 together with a fitted generalised linear model with a reciprocal link function. A slight increase in inter-event times is seen (equal to a decrease in intensity).

Table 2. Estimated time dependent parameters, $\sigma(t)$ and $\xi(t)$, in the non-stationary Poisson point process models using threshold $u=0.1 \mathrm{Mm}^{3}$. Log-likelihoods for the different models are also given. Time is transformed to interval $[0,1]$.

\begin{tabular}{lc}
\hline Model & $\begin{array}{c}\text { (Log-likelihood) } \\
\text { Estimates }\end{array}$ \\
\hline Stationary & $(-75.30)$ \\
Scale $\sigma$ & 1.04 \\
Shape $\xi$ & 1.00 \\
Linear in scale & $(-75.22)$ \\
Scale $\sigma_{0}, \sigma_{1}$ & 0.870 .32 \\
Shape $\xi$ & 1.00 \\
Linear in shape & $(-75.29)$ \\
Scale $\sigma$ & 1.04 \\
Shape $\xi_{0}, \xi_{1}$ & 0.950 .09 \\
Linear in scale and shape & $(-75.22)$ \\
Scale $\sigma_{0}, \sigma_{1}$ & 0.850 .37 \\
Shape $\xi_{0}, \xi_{1}$ & $1.04-0.08$ \\
\hline
\end{tabular}

other thresholds. However, the trends do not significantly differ from zero.

To assess a possible trend in damage size we allow for time-dependent shape and scale parameters. Table 2 gives parameter estimates together with log-likelihood for the four different temporal trend models together with the estimates for the model without trend (time is transformed to interval $[0,1])$. The models indicate an increase in scale, $\sigma$, and an almost constant shape, $\xi$, of the distribution of excesses. Comparing log-likelihood for the different models gives, however, 

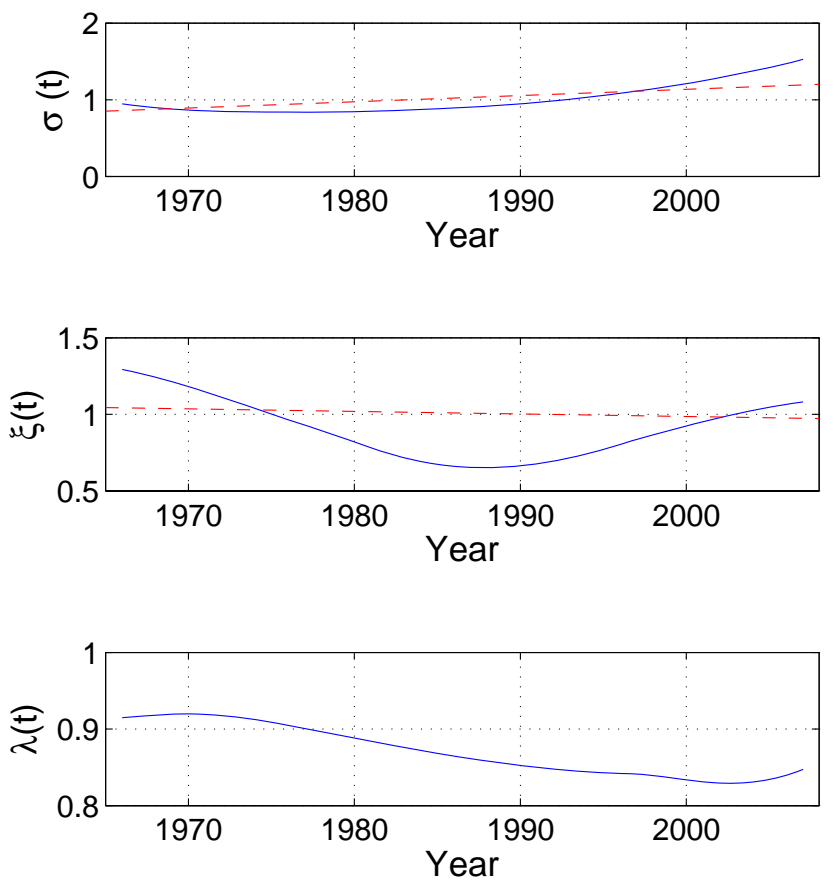

Fig. 6. Local likelihood estimates of the generalised Pareto scale, $\sigma$, shape, $\xi$, parameters and the intensity, $\lambda$, using a biweight kernel with bandwidth 0.6 (solid line) and corresponding estimates using the parametric approach with temporal model (iii) (dashed line).

that non of the time dependent models is significantly better than the stationary model.

A second approach to model a temporal trend is to use the non-parametric method described above. Numerically maximising the weighted local-likelihood function, Eq. (5), for different time points, using a biweight kernel with bandwidth $h=0.6$, give the estimates of $\sigma(t), \xi(t)$ and $\lambda(t)$ plotted in Fig. 6. From the plot it can be seen that there is an increasing trend in the scale parameter and that the shape parameter decreases from the beginning of the period to mid 80-ties and then increases at the end of the period. The intensity decreases slightly over the period.

\section{Discussion and conclusions}

Normalised storm damage data for the period 1965-2007 has been analysed using a Poisson point process model with generalised Pareto distributed excesses. Damage data show strong support for a heavy tailed distribution with a shape parameter approximately equal to one which gives great variability in amplitude for the most extreme events and explains why the "worst" storm damage is likely to come as a "surprise". This can be illustrated by calculating the median of the next worst storm damage event in Sweden. Using parameter estimates $(\hat{\xi}, \hat{\sigma})=(1.00,1.04)$, the median of the next worst storm damage is $140 \mathrm{Mm}^{3}$ or twice the size of the damage caused by the severe storm in January 2005 . This can be compared with normalised damage data for the so far worst storm (January 2005) and second worst storm (November 1969) which has a ratio of 2.6. Similar heavy tailed distributions have been found in other studies of storm damage (Rootzén and Tajvidi, 1997; McNeil and Saladin, 2000; Katz, 2006).

Available damage records show that reported forest storm damage has increased dramatically since the beginning of the 20th century. The large increase in coniferous forest as well as an increased susceptibility may be some of the reason. Yet, these factors do not seem sufficient to explain the strong increase seen in Fig. 1. The main reason for the increase is probably inhomogeneity in recorded data. This holds especially for data from the first half of the 20th century, when there might have been unreported storms, or reported storms with only part of the damage volume reported.

The analysis gives no conclusive evidence of an increasing temporal trend in the normalised storm damage data for the period 1965 to January 2007. However, as pointed out above, the number of available damage events used in the analysis is relatively small and therefore the uncertainty is large. The most severe damage events, in Sweden as well as in Europe as whole, occurred at the end of the period. It can not be excluded that this marks the beginning of increased damage due the climate change.

Acknowledgements. This analysis was supported financially by the Swedish Emergency Management Agency through a grant for the research programme FRIVA (Framework Programme for Risk and Vulnerability Analysis). The forest damage data collection was supported by the MICE-project, financed by the European Commission under contract EVK2-CT-00118.

The authors would like to thank professors G. Lindgren, at the Dept. of Mathematical Statistics, Lund University and L. Bärring, at the Dept. of Physical Geography and Ecosystems Analysis, Lund University, and Rossby Centre, SMHI, for valuable comments and advice.

Edited by: A. Mugnai

Reviewed by: two anonymous referees

\section{References}

Alexandersson, H. and Ivarsson, K.-I.: Januaristormen 2005, SMHI, 2005.

Alexandersson, H., Tuomenvirta, H., Schmith, T., and Iden, K. Trends of storms in NW Europe derived from an updated pressure data set, Climate Res., 14, 71-73, 2000.

Bärring, L. and von Storch, H.: Scandinavian storminess since about 1800, Geophys. Res. Lett., 31, L20202, doi:10.1029/2004GL020441, 2004.

Coles, S.: An Introduction to Statistical Modeling of Extreme Values, Springer-Verlag, London, UK, 2001. 
Coutts, M., Nielsen, C., and Nicoll, B.: The development of symmetry, rigidity and anchorage in the structural root system of conifers, Plant and Soil, pp. 1-15, 1999.

Danjon, F., Fourcaud, T., and Bert, D.: Root architecture and windfirmness of mature Pinus pinaster, New Phytol., pp. 387-400, 2005.

Davison, A. C. and Ramesh, N. I.: Local likelihood smoothing of sample extremes, J. Roy. Stat. Soc. B, 62, 191-208, 2000.

Hall, P. and Tajvidi, N.: Nonparametric analysis of temporal trend when fitting parametric models to extreme-value data, Stat. Sci., 15, 153-167, 2000.

Hollgren, C. A.: Juldagsnattens storm i Halland, Skogsvårdsföreningens Tidskrift, pp. 38, 39, 1903.

Holmberg, L.-E.: Sammanställning av stormskador på skog i Sverige under de senaste 210 åren, Skogsstyrelsen, Rapport, 2005.

Katz, R.: Stochastic modeling of hurricane damage under climate change, Laboratoire des Sciences du Climate et de l'Environnement, Gif-sur-Yvette, http://www.isse.ucar.edu/HP_ rick/pdf/lsce.pdf, 2006.

Leadbetter, M. R., Lindgren, G., and Rootzen, H.: Extremes and related properties of random sequences and processes, SpringerVerlag, NewYork, 1983.

McNeil, A. J. and Saladin, T.: Developing Scenarios for Future Extreme Losses Using the POT Model, in: Extremes and Integrated Risk Management, edited by: Embrechts, P., RISK books, London, 2000.

NFI06: Trend for total standing volume since 1920., Riksskogstaxeringen (National Forest Inventory), http: //www-riksskogstaxeringen.slu.se/.

Nilsson, C., Stjernquist, I., Bärring, L., Schlyter, P., Jönsson, A. M., and Samuelsson, H.: Recorded storm damage in Swedish forests 1901-2000, Forest Ecology and Management, 199, 165-173, 2004.
Peltola, H., Kellomäki, S., and Väisänen, H.: Model computations of the impact of climate change on the windthrow risk of trees, Climate Change, pp. 17-36, 1999a.

Peltola, H., Kellomäki, S., Väisänen, H., and Ikonen, V. P.: A mechanistic model for assessing the risk of wind and snow damage to single trees and stands of Scots pine, Norway spruce, and birch., Can. J. Forest. Res., 29, 647-661, 1999 b.

Peltola, H. Z. H., Talkkari, A., Venäläinen, A., Strandman, H., Kellomäki, S., and Wang, K.: Influence of clear-cutting on the risk of wind damage at forest edges, Forest Ecol. Manag., pp. 77-88, 2004.

Persson, P.: Windthrow in forests - Its causes and effect of forestry measures, Ph.D. thesis, Royal College of Forestry, Stockholm, 1975.

Rootzén, H. and Tajvidi, N.: Extreme value statistics and wind storm losses: A case study, Scand. Actuarial Journal, 1, 70-94, 1997.

Schelhaas, M.-J., Nabuurs, G.-J., and Schuck, A.: Natural disturbances in the European forests in the 19th and 20th centuries, Global Change Biol., 9, 1620-1633, 2003.

Skogsstyrelsen: Stormen 2005 - en skoglig analys, Meddelande 1, 2006a.

Skogsstyrelsen: Analys av riskfaktorer efter stormen Gudrun, Rapport 8, 2006b.

Skogsstyrelsen: Swedish Statistical Yearbook of Forestry, 2006c.

Sotter, K.: Stormskador i Sveriges skogar under åren 1871-1955, Unpublished report, 1956.

Venäläinen, A., Zeng, H., Peltola, H., Talkkari, A., Strandman, H., Wang, K., and Kellomäki, S.: Simulations of the influence of forest management on wind climate on a regional scale, Agricul. For. Met., pp. 149-158, 2004. 